\title{
The role of immunity in mosquito-induced attenuation of malaria virulence
}

\author{
Margaret J Mackinnon ${ }^{1,2}$
}

\begin{abstract}
A recent study found that mosquito-transmitted (MT) lines of rodent malaria parasites elicit a more effective immune response than non-transmitted lines maintained by serial blood passage (non-MT), thereby causing lower parasite densities in the blood and less pathology to the host. The authors attribute these changes to higher diversity in expression of antigen-encoding genes in MT cf. non-MT lines. Alternative explanations that are equally parsimonious with these new data, and results from previous studies, suggest that this conclusion may be premature.
\end{abstract}

Keywords: Malaria, Virulence, Mosquito transmission, Immunity

\section{Background}

Many studies have shown that when parasite lines of the rodent malaria Plasmodium chabaudi or other malaria species are transmitted through mosquitoes, their virulence and asexual replication rate in the blood is reduced [1-6]. This phenomenon is most obvious when lines have been maintained in the laboratory by serial blood passage (SBP) without mosquito transmission: this is because continuous serial passage leads to progressively higher virulence and replication rates [1,6-13]. Spence et al. [6] have recently re-visited the phenomenon of mosquito-induced virulence attenuation, in particular addressing whether it alters the parasite's interaction with the immune system of its host. They found that MT parasites induce a less effective immune response than their non-MT counterparts, and further found differences between MT and non-MT lines in the expression of a set of putative antigen-encoding genes.

\section{Interactions between evolved virulence, immunity and mosquito transmission}

The family of genes that Spence et al. [6] found to be differentially expressed between MT and non-MT lines encode a large, highly variable set of antigens thought to be displayed on the surface of the parasite-infected red cell where they interact with the immune system. NonMT lines expressed a few members of this gene family

\footnotetext{
Correspondence: mmackinnon@kemri-wellcome.org

${ }^{1}$ KEMRI-Wellcome Trust Research Programme, PO Box 230, Kilifi, Kenya

${ }^{2}$ Centre for Tropical Medicine, Nuffield Department of Medicine, University of Oxford, Oxford OX3 7LJ, UK
}

at high frequency and the remainder at low frequency whereas MT lines expressed all members approximately equally. Spence et al.'s [6] observation implies that during mosquito transmission the expression pattern of the antigenic repertoire is re-set, thereby restoring antigenic diversity and reducing the dominance of certain antigenic types that arise during serial blood passage.

Does this resetting render MT parasites more controllable by the immune system, or is it just that MT parasites are less intrinsically virulent? In previous experiments studying the evolution of parasite virulence in the same experimental model used by Spence et al. (Plasmodium chabaudi in C57/B16 laboratory mice) parasite lines were evolved by SBP through either immunized or naïve mice and, at the end, virulence of the evolved lines was measured, both in immunized and naïve mice, and both before and after mosquito transmission [1]. Before mosquito transmission, parasites evolved in immunized mice ('I-lines') were found to be more virulent and faster replicating than those evolved in naïve mice ('N-lines'). This held whether or not virulence was measured in naïve or immunized mice. After mosquito transmission, I-lines were still more virulent and faster replicating than $\mathrm{N}$-lines when measured in naïve mice. These results suggested that immune selection had generated higher levels of intrinsic virulence and replication, and that the changes were genetically 'hard-wired'.

However, when the I-lines were compared to the Nlines in pre-immunized mice, the differences disappeared. In the light of new data from Spence et al. [6], it 
is hypothesized here that selection in immunized mice favours parasites with rare antigenic types. When expression of the antigenic repertoire is re-set in mosquitoes, as found by Spence et al. [6], these rare types would switch off, or down, their expression. This would thus eliminate the I-lines' replication advantage and higher virulence when measured in pre-immunized mice. If it is assumed that these rarer antigenic types were selectively favoured in immunized mice because they were more invisible to the immune system of a non-immunized mouse, these data fit well with Spence et al.'s [6] interpretation that mosquitoes induce changes to the way the parasite is 'seen' by the immune system.

However, several alternative explanations that invoke changes to the parasite's intrinsic virulence, as opposed to the immunity it provokes, are similarly parsimonious with the data of Spence et al. [6] and from previous experiments $[1,2]$. Severe population bottlenecking during mosquito passage will eliminate most new highvirulence mutants expected to accumulate during SBP. As theory predicts [14] and experiments have shown $[2,15]$, bottlenecking causes a general, albeit variable, reduction in virulence. Alternatively, SBP might create sub-populations of 'short-sighted, dead-end' [16] virulence mutants which grow fast but cannot transmit. The presence of such mutants would not be detected in a mixed population of predominantly transmissible parasites. However, weeding them out during transmission would cause a reduction in virulence, as observed.

\section{Conclusions}

Although virulence attenuation in laboratory models of malaria [1-6] is highly artificial since all natural malaria infections are transmitted via the mosquito, the Spence et al. [6] study takes us one step closer towards a molecular understanding of malaria parasite virulence. Just how their observed molecular changes translate to reduced virulence is still open to debate. Delineating among competing explanations is critical because of mounting evidence in Plasmodium falciparum, the most deadly of the human malaria parasites, that certain subsets of the variable surface antigens are highly pathogenic [17-20] thus creating hope for an 'anti-virulence' vaccine.

\section{Competing interests}

The author declares that she has no competing interests.

\section{Acknowledgements}

MM received support from the Wellcome Trust, The Royal Society of London and the Leverhulme Trust during the period when these ideas were formulated. Members of Andrew F. Read's research group are thanked for numerous discussions of this subject over the years.

\section{References}

1. Mackinnon MJ, Read AF: Immunity promotes virulence evolution in a malaria model. PLOS Biol 2004, 2:E230

2. Mackinnon MJ, Bell A, Read AF: The effects of mosquito transmission and population bottlenecking on virulence, multiplication rate and rosetting in rodent malaria. Int J Parasitol 2005, 35:145-153.

3. Walliker D, Sanderson A, Yoeli M, Harant J, Hargreaves B: A genetic investigation of virulence in a rodent malaria parasite. Parasitology 1976, 72:183-194.

4. Knowles G, Walliker D: Variable expression of virulence in the rodent malaria parasite Plasmodium yoelii yoelii. Parasitology 1980, 81:211-219.

5. Gilks CF, Walliker D, Newbold Cl: Relationships between sequestration, antigenic variation and chronic parasitism in Plasmodium chabaudi chabaudi - a rodent malaria model. Parasite Immunol 1990, 12:45-64

6. Spence PJ, Jarra W, Levy P, Reid AJ, Chappell L, Brugat T, Sanders M, Berriman M, Langhorne J: Vector transmission regulates immune control of Plasmodium virulence. Nature 2013, 498:228-231.

7. James SP, Nicol WD, Shute PG: Clinical and parasitological observations on induced malaria. Proc R Soc Med 1936, 29:879-894.

8. Greenberg J, Kendrick LP: Some characteristics of Plasmodium berghei passed within inbred strains of mice. J Parasitol 1956, 43:423-427.

9. Sergent $E$, Poncet $A$ : Des variations expérimentales de la virulence de Plasmodium berghei: exaltation-atténuation-mithridatisme. Arch Inst Pasteur Alger 1959, 37:228-234.

10. Galli L, Brambilla E: Progressivo aumento della virulenza di un ceppo di Plasmodium berghei. Riv Parassitologia 1967, 28:173-176.

11. Hartley EG: Increased virulence of Plasmodium cynomolgi bastionelli in the rhesus monkey. Trans R Soc Trop Med Hyg 1969, 63:411-412.

12. Dearsly $A L$, Sinden RE, Self IA: Sexual development in malarial parasites: gametocyte production, fertility and infectivity to the mosquito vector. Parasitology 1990, 100:359-368.

13. Mackinnon MJ, Read AF: Selection for high and low virulence in the malaria parasite Plasmodium chabaudi. Proc Biol Sci 1999, 266:741-748.

14. Bergstrom CT, McElhaney P, Real LA: Transmission bottlenecks as determinants of virulence in rapidly evolving pathogens. Proc Natl Acad Sci USA 1999, 96:5095-5100.

15. Alger NE, Branton M, Harant J, Silverman PH: Plasmodium berghei NK65 in the inbred $A / J$ mouse: variations in virulence in $P$. berghei demes. J Protozool 1971, 18:598-601.

16. Levin BR, Bull JJ: Short-sighted evolution and the virulence of pathogenic microorganisms. Trends Microbiol 1994, 2:76-81.

17. Lavstsen T, Turner L, Saguti F, Magistrado P, Rask TS, Jespersen JS, Wang CW, Berger SS, Baraka V, Marquard AM, Seguin-Orlando A, Willerslev E, Gilbert MT, Lusingu J, Theander TG: Plasmodium falciparum erythrocyte membrane protein 1 domain cassettes 8 and 13 are associated with severe malaria in children. Proc Natl Acad Sci USA 2012, 109:E1791-E1800.

18. Claessens A, Adams Y, Ghumra A, Lindergard G, Buchan CC, Andisi C, Bull PC, Mok S, Gupta AP, Wang CW, Turner L, Arman M, Raza A, Bozdech Z, Rowe JA: A subset of group A-like var genes encodes the malaria parasite ligands for binding to human brain endothelial cells. Proc Natl Acad Sci USA 2012, 109:E1772-E1781.

19. Avril M, Tripathi AK, Brazier AJ, Andisi C, Janes JH, Soma VL, Sullivan DJ Jr, Bull PC, Stins MF, Smith JD: A restricted subset of var genes mediates adherence of Plasmodium falciparum-infected erythrocytes to brain endothelial cells. Proc Natl Acad Sci USA 2012, 109:E1782-E1790.

20. Warimwe GM, Fegan G, Musyoki JN, Newton CR, Opiyo M, Githinji G, Andisi C, Menza F, Kitsao B, Marsh K, Bull PC: Prognostic indicators of lifethreatening malaria are associated with distinct parasite variant antigen profiles. Sci Trans/ Med 2012, 4:129ra45.

doi:10.1186/1475-2875-13-25

Cite this article as: Mackinnon: The role of immunity in mosquitoinduced attenuation of malaria virulence. Malaria Journal 2014 13:25. 